\title{
ENANTIOSELECTIVE ADDITION OF DIETHYL ZINC TO BENZALDEHYDE CATALYZED BY TI(IV) AND GLUCOSE DERIVATIVES
}

\author{
JOSÉ PARADA*, JORGE MENDOZA, FRANCY CISTERNAS, ANGEL EGUILUZ \\ Departamento de Química Inorgánica y Analítica, Facultad de Ciencias Químicas y Farmacéutica, Universidad de Chile.
} (Received: November 26, 2009 - Accepted: July 7, 2010)

\begin{abstract}
D-Glucose derivatives 1,2:5,6-di-O-isopropyline-a-D-glucofuranose (1) and 1,2-O-isopropyline-a-D-glucofuranose (2) with Ti(IV) are chiral catalysts in the addition of diethylzinc to benzaldehyde. The Ti(IV)-carbohydrate catalytic system is optimal with excess Ti(IV) and substoichiometric carbohydrate and $\mathbf{2}$ is the more active chiral catalyst probably because this derivative acts as a bidentate ligand in the proposed reaction. The arrangement of OH groups is crucial in determining the configuration of the alcohol product.
\end{abstract}

Keywords: diethylzinc, glucose derivatives, 1- phenyl-1-propanol, Ti (IV)-carbohydrate

\section{INTRODUCTION}

Enantioselective addition of organometallic compounds to aldehydes or prochiral ketones is an important synthetic method for preparing enantiopure chiral alcohols, ${ }^{1,2}$ which are biologically active natural products, ${ }^{3}$ and are precursors of pharmaceutical drugs and insecticides. ${ }^{4}$

Direct addition of diethylzinc to aldehydes and ketones is extremely slow, ${ }^{1-3}$ but is accelerated by some substoichiometric chiral compounds. ${ }^{1-3,5,6}$ For example with a chiral diol and a $\mathrm{Ti}(\mathrm{IV})$ salt $\left(\mathrm{eg} \mathrm{Ti}\left(\mathrm{O}^{\mathrm{i}} \mathrm{Pr}\right)_{4}\right)$, the reaction gives high yield and enantioselectivity..$^{7-14}$ We have recently catalyzed the homogeneous selective addition of diethylzinc to benzaldehyde ${ }^{15}$.

The catalyst was the mixture of $10 \% \mathrm{~mol}$ of a diol derivative of D-xylose (3) relative to the aldehyde with 1 equivalent of $\mathrm{Ti}(\mathrm{O} \mathrm{OPr})_{4}$. After acid hydrolysis 1-phenyl-1-propanol was in $90 \%$ yield with $45 \%$ enantiomeric excess (ee) of the $\mathrm{S}$ isomer. Without $\mathrm{Ti}\left(\mathrm{O}^{\mathrm{P} P r}\right)_{4}$ this reaction gives low yield and little enantioselectivity. We propose that the catalyst is a dinuclear compound of the Ti(IV)-derivative (3).

The carbohydrate structure was modified in the present work to determine the catalytic capacity of the Ti(IV)-carbohydrate systems in the enantioselective addition of Et $\mathrm{Zn}$ to benzaldehyde. The arrangement of $\mathrm{OH}$ groups in the carbohydrate derivative was modified from an inner arrangement, external to the furasonic ring of carbohydrate (3), to two $\mathrm{OH}$ groups external to that ring (2). In addition, a study was carried out of the difference between carbohydrates $(\mathbf{2}$ and $\mathbf{3})$, which act as bidentate ligands in relation to monodentate (1) in the Ti(IV)-carbohydrate Ti(IV)-carbohydrate systems. Finally, the extent to which the Ti(IV)/carbohydrate ratio affects enantioselectivity in the catalysis under study was also investigated.
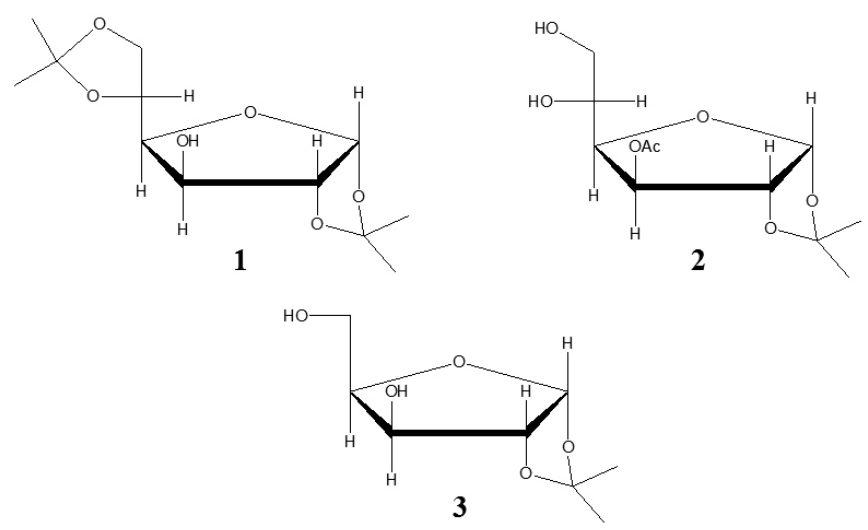

\section{Experimental}

All reagents and solvents were analytical grade. Carbohydrate $\mathbf{1}$ was from Aldrich. Carbohydrate $\mathbf{2}$ was synthesized according to the literature procedure. ${ }^{16}$
Enantioselective addition of diethylzinc to benzaldehyde catalyzed by the Ti(IV-carbohydrate (1 and 2) system

Compound 1 (OR 2) in variable sub-stoichiometric amounts $0.05,0.1$ and $0.2 \mathrm{mmol}(5.0 \%, 10.0 \%$, and $20.0 \% \mathrm{~mol}$ with respect to benzaldehyde) was in a dry $50 \mathrm{~mL}$ Schlenk tube, with a silicone stopper, and air was removed by purging three times with nitrogen under vacuum. The following were then added successively: $0.3 \mathrm{~mL}(1 \mathrm{mmol})$ titanium tetraisopropoxide, $2.5 \mathrm{~mL}$ dichoromethane, $3 \mathrm{~mL}(3 \mathrm{mmol})$ of a $1 \mathrm{~mol} \cdot \mathrm{L}^{-1}$ solution of $\mathrm{Et}_{2} \mathrm{Zn}$ in hexane and finally $0.1 \mathrm{~mL}(1 \mathrm{mmol})$ benzaldehyde.

The reaction proceeded with stirring for 3 and 6 hours at room temperature, and was stopped by adding a saturated solution of ammonium chloride (forming ethane and a white precipitate of zinc oxide). The mixture was transferred to a separatory funnel and the product was extracted with three $10 \mathrm{~mL}$ portions of ethyl ether, and dried with anhydrous $\mathrm{MgSO}_{4}$. The organic phase was used to analyze and quantify the products obtained in each reaction.

\section{Catalysis Product Analysis and quantification}

A sample, $0.4 \mu \mathrm{L}$, was injected into an HP 5890 series II gas chromatograph equipped with an Allchrom plus program and a methylsilicone-gum-type $5 \mathrm{~m}$ x $0.53 \mathrm{~mm} \times 2.65 \mu \mathrm{m}$ column. Working conditions were:

Initial temperature, $100{ }^{\circ} \mathrm{C}$; initial time, $5 \mathrm{~min}$; rate, $20^{\circ} \mathrm{C} / \mathrm{min}$; final time, 18 min; pressure, 10 psi.

$\mathrm{tR}($ benzaldehyde $)=7.8 \mathrm{~min} \quad \mathrm{tR}(1-$ phenyl-1-propanol $)$

$=11.9 \mathrm{~min}$

Conversion \% was determined from the ratio of areas of product and benzaldehyde peaks.

Enantiomeric excess was determined with a Supelco b-Dex 120: $30 \mathrm{~m} \mathrm{x}$ $0.25 \mathrm{~mm} \times 0.25 \mu \mathrm{m}$ chiral capillary column. Working conditions were:

Starting temperature, $100^{\circ} \mathrm{C}$; starting time, $0 \mathrm{~min}$; temperature gradient, $1^{\circ}$ $\mathrm{C} / \mathrm{min}$; pressure, $10 \mathrm{psi}$. $\min$.

$t_{R}(R-1-$ phenyl-1-propanol $)=28.7$ min. $\quad t_{R}(S-1-$ phenyl-1-propanol $)=29.5$

Enantioselectivity (\%ee) was determined from the respective areas of peaks of R and S of the chiral alcohols.

The dominant configuration of the products was given by the sign of the optical rotation measured at $20^{\circ} \mathrm{C}$ on a Perkin Elmer PE 241 polarimeter with the literature data. ${ }^{17}$

\section{RESULTS AND DISCUSSION}

Enantioselective addition of diethylzinc to benzaldehyde catalyzed by the Ti(IV)-carbohydrate (1 and 2) systems

Table 1 summaries the most important results in enantioselective addition of Et $\mathrm{Zn}$ to benzaldehyde catalyzed by Ti(IV) and derivatives $\mathbf{1}$ and $\mathbf{2}$, synthesized following the literature method ${ }^{16}$ were used in substoichiometric amounts of mol $5.0 \%, 10.0 \%$, and $20.0 \%$ relative to benzaldehyde with or without $\mathrm{Ti}(\mathrm{IV})$. The solvent was $\mathrm{CH}_{2} \mathrm{Cl}_{2}$, previously found to be the most adequate for the Ti(IV) plus derivative 3 system). ${ }^{15}$ In this preliminary study it was also shown that catalysis was effective at room temperature and reaction 
times of 3 to $6 \mathrm{~h}$ which gave a high conversion of benzaldehyde into 1-phenyl1-propanol. The longer reaction times allowed decomposition of the chiral alcohol (Table 1).

The absence of carbohydrates $\mathbf{1}$ and $\mathbf{2}$ decreased conversion of benzaldehyde to 1-phenyl-1-propanol, reaching $45 \%$ at $6 \mathrm{~h}$ reaction time (Table 1). Without Ti(IV) this conversion is less than $10 \%$ after $6 \mathrm{~h}$.

The Ti(IV)-carbohydrate $\mathbf{1}$ and $\mathbf{2}$ catalytic systems $\mathbf{2}$ increased conversion which was independent of the utilized concentration of derivatives $\mathbf{1}$ or 2, giving $>90 \%$ conversion after $6 \mathrm{~h}$, as previously found for the Ti(IV)carbohydrate 3 system. ${ }^{15}$

All the reactions under study show a high conversion of benzaldehyde to 1-phenyl-1-propanol with Ti(IV) and derivatives 1 or $\mathbf{2}$ (Table 1). The yield was independent of the $\mathrm{OH}$ group arrangement or of the carbohydrate being a monodentate (1) or bidentate ( $\mathbf{2}$ and $\mathbf{3}$ ) ligand. Therefore a high conversion rate of benzaldehyde to 1-phenyl-1-propanol in this reaction requires the simultaneous presence of Ti(IV) and derivative $\mathbf{1}$ or $\mathbf{2}$.

However, all the Ti(IV)-carbohydrate $\mathbf{1}$ or $\mathbf{2}$ systems were enantoselective catalysts for $\mathrm{Et}_{2} \mathrm{Zn}$ addition to benzaldehyde (Table 1). Without carbohydrates 1 and $\mathbf{2}$, the reaction gave very low enantioselectivity (entries 1 and 5 Table 1). Without Ti(IV), enantioselectivity was very low. Carbohydrate 1 plus Ti(IV) as catalyst gave a maximum enantioselectivity $(35 \%$ ee) with $0.1 \mathrm{mmol}(10 \%$ mol of derivative 1) and $1 \mathrm{mmol}$ Ti(IV) after $6 \mathrm{~h}$ (entry 7, Table 1). A smaller amount of derivative $\mathbf{1}(5 \% \mathrm{~mol})$ slightly decreased enantioselectivity $(31 \%$ ee $)$ (entry 6, Table 1$)$ while an increase in derivative $1(20 \% \mathrm{~mol})$ had no significant effect on the enantioselectivity (entry 8, Table 1). Derivative 2 gave higher enantioselectivity than carbohydrate $\mathbf{1}$, reaching maximum enantioselectivity (57\% ee) with $10 \%$ mol of derivative 2 (entry 13 , Table 1 ) A smaller $(5 \%$ mol) or larger $(20 \% \mathrm{~mol})$ amount of derivative 2 slightly decreased enantioselectivity in both cases, reaching $48 \%$ ee at $6 \mathrm{~h}$ reaction time (entry 12, Table 1), i.e., than that with the Ti(IV)-carbohydrate $\mathbf{1}$ system. These results are similar to those obtained with the Ti(IV)-derivative 3 catalytic system, which gave a maximum enantiomeric excess of $45 \%,{ }^{15}$ indicating that for maximum ensntioselectivity, the Ti(IV)-carbohydrate catalytic system must contain a bidentate ligand ( 2 or 3). The possible dinuclear catalyst, Ti(IV)-carbohydrate (2 or $\mathbf{3}$ ) (Scheme 1) generated within the reaction should be rigid, enhancing steric and electronic factors favoring a predominant configuration of the resulting 1-phenyl-1propanol. The probable mechanism is shown later.

Table 1: Addition of $\mathrm{Et}_{2} \mathrm{Zn}$ to benzaldehyde catalyzed by Ti(IV)carbohydrates $\mathbf{1}$ and $\mathbf{2}^{\text {a) }}$.<smiles>CCC(C)c1ccccc1</smiles>

\begin{tabular}{|c|c|c|c|cc|}
\hline Entry & $\begin{array}{c}\text { Reaction } \\
\text { Time(h) }\end{array}$ & $\begin{array}{c}\text { Derivative } \\
(\% \text { mol })^{\mathrm{b})}\end{array}$ & $\begin{array}{c}\text { Conversión } \\
(\mathbf{\%})\end{array}$ & ee $^{\mathrm{d})}(\%)$ (Config. $)^{\mathrm{e})}$ \\
\hline 1 & 3 & $\mathbf{0}$ & 15 & 2 & $(\mathrm{R})$ \\
\hline 2 & 3 & $\mathbf{1}(5.0)$ & 72 & 25 & $(\mathrm{R})$ \\
\hline 3 & 3 & $\mathbf{1}(10.0)$ & 79 & 35 & $(\mathrm{R})$ \\
\hline 4 & 3 & $\mathbf{1}(20.0)$ & 60 & 34 & $(\mathrm{R})$ \\
\hline 5 & 6 & $\mathbf{0}$ & 45 & 3 & $(\mathrm{R})$ \\
\hline 6 & 6 & $\mathbf{1}(5.0)$ & 90 & 31 & $(\mathrm{R})$ \\
\hline 7 & 6 & $\mathbf{1}(10.0)$ & 94 & 35 & $(\mathrm{R})$ \\
\hline 8 & 6 & $\mathbf{1}(20.0)$ & 93 & 30 & $(\mathrm{R})$ \\
\hline 9 & 3 & $\mathbf{2}(5.0)$ & 87 & 37 & $(\mathrm{R})$ \\
\hline 10 & 3 & $\mathbf{2 ( 1 0 . 0 )}$ & 83 & 43 & $(\mathrm{R})$ \\
\hline 11 & 3 & $\mathbf{2 ( 2 0 . 0 )}$ & 82 & 51 & $(\mathrm{R})$ \\
\hline 12 & 6 & $\mathbf{2 ( 5 . 0 )}$ & 91 & 48 & $(\mathrm{R})$ \\
\hline 13 & 6 & $\mathbf{2}(10.0)$ & 95 & 57 & $(\mathrm{R})$ \\
\hline 14 & 6 & $\mathbf{2}(20.0)$ & 91 & 54 & $(\mathrm{R})$ \\
\hline
\end{tabular}

a) Reaction with $1 \mathrm{mmol}$ benzaldehyde and $3 \mathrm{mmol} \mathrm{Et}_{2} \mathrm{Zn}$ and $1 \mathrm{mmol}$ $\mathrm{Ti}\left(\mathrm{O}^{\mathrm{P} P r}\right)_{4}{ }^{\text {b) }}$ Mol percentages referred to benzaldehyde.${ }^{\mathrm{c}}$ Determined by GLC d) Determined by GLC. with b-DEX 120 column. ${ }^{\text {e) The configuration was }}$ determined by comparison of the literature values. ${ }^{17}$
All the Ti(IV)-carbohydrate catalytic systems $\mathbf{1}$ or $\mathbf{2}$ preferably gave R 1-phenyl-1-propanol (Table 1), unlike that with the Ti(IV)-derivative 3 system, where the prevailing configuration of 1-phenyl-1-propanol is $\mathrm{S},{ }^{15}$ indicating that in the Ti(IV)-carbohydrate (2 or 3) (Scheme 1) the arrangement of OH groups of carbohydrate ( 2 or $\mathbf{3}$ ) determines the configuration (R or S) of 1-phenyl-1-propanol.

The effect of the Ti(IV)/carbohydrate ratio on \% ee is shown in Figure 1. The Ti(IV)-carbohydrate (2) system was chosen because it produced the highest enantioselectivity in the reactions studied (Table1). At Ti(IV)/derivative 2 ratios between 0 and 3, enantioselectivity is only $10 \%$ ee, between 3 and 10 , it increases to a maximum, and higher ratios slightly decrease enantioselectivity. With the $\mathrm{Ti}(\mathrm{IV}) /$ carbohydrate ratio of 10 , the maximum enantioselectivity was obtained in all the reactions examined (Table1). These results are consistent with those in the literature,, 10 and existence of the Ti(IV)-carbohydrate 2 dinuclear catalytic species (Scheme 1).
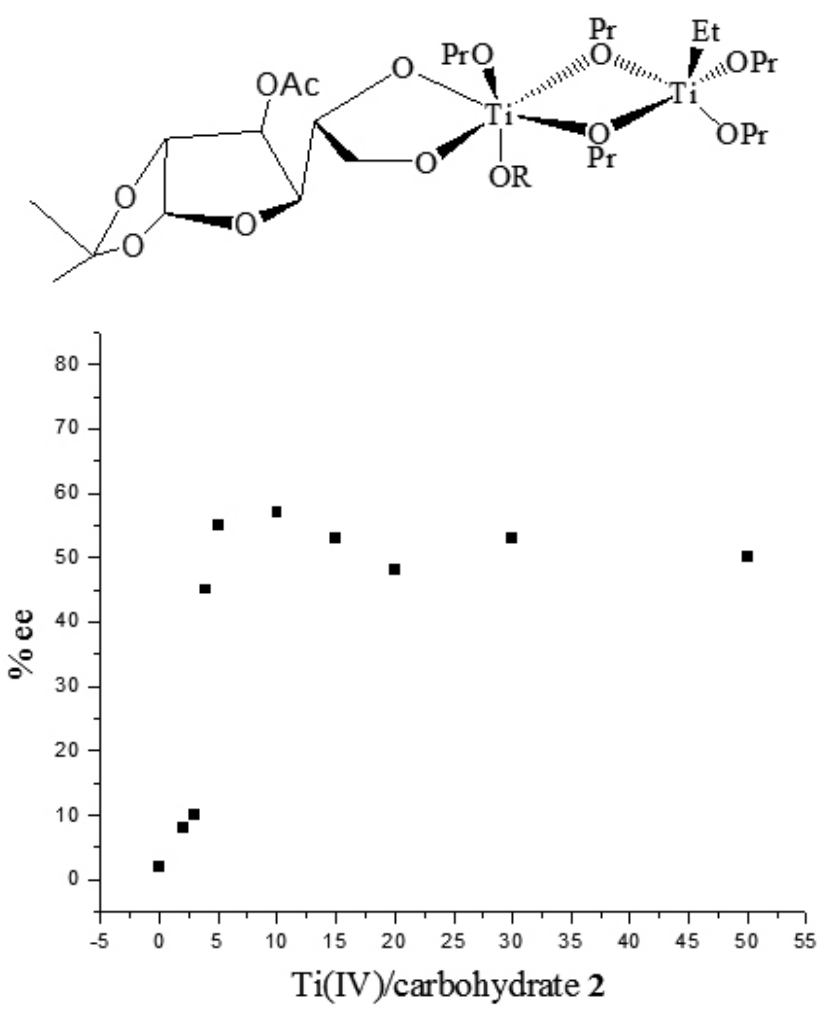

Figure 1. Enantiomeric excess (\%ee) of R-1-phenyl-1-propanol at different $\mathrm{Ti} /$ carbohydrate ratios, obtained under the same conditions as those in Table 1 at $6 \mathrm{~h}$ reaction time.

Probable reaction mechanism in enantioselective addition of $\mathrm{Et}_{2} \mathrm{Zn}$ to benzaldehyde catalyzed by the Ti(IV)-derivative 2

In the probable reaction mechanism in enantioselective addition of $\mathrm{Et}_{2} \mathrm{Zn}$ to benzaldehyde, starting from dimer I (similar compounds are described in the literature) (Scheme 2), ${ }^{9-15}$ dinuclear III would result. This compound would react with 1 mol benzaldehyde to form dinuclear IV. Here, the ethyl group would be preferably transferred to one of the faces of the carbonyl group of benzaldehyde. This would be determined by the position adopted by the carbohydrate in IV. This position would be caused by the different arrangement of the $\mathrm{OH}$ groups present in carbohydrates ( $\mathbf{2}$ and $\mathbf{3}$ ). On the other hand, the possible IV with carbohydrate 1 would be flexible, as a result of 1 being coordinated by only one $\mathrm{OH}$. This would facilitate the ethyl group attack on both faces of the carbonyl group of benzaldehyde, thus producing a decrease in the reaction enantioselectivity. A rearrangement in IV would generate IV, which in turn would produce $(\mathrm{PhEtC}-\mathrm{O}) \mathrm{Ti}(\mathrm{O} \mathrm{Pr})$ and $1 / 2 \mathrm{~mol}$ dimer $\mathbf{I}$. Regeneration of dimer I would cause the complete start of the catalytic cycle, which would repeat itself until the reaction were stopped by acid hydrolysis and 1-phenyl-1-propanol were produced in a predominant configuration. 


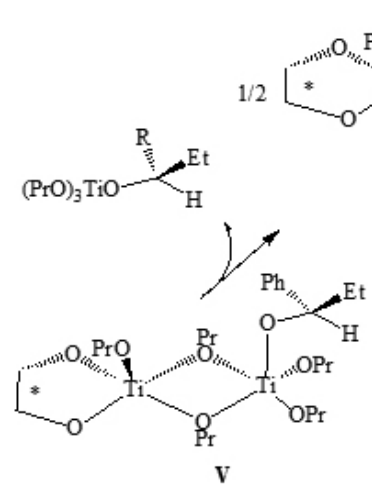

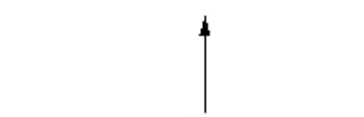

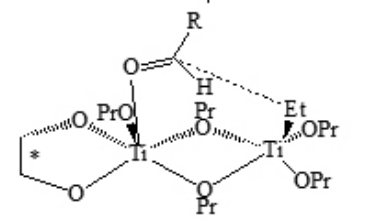

RCHO<smiles>C1CCCC1</smiles>

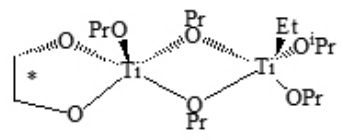

IV

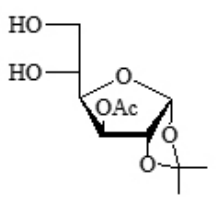

\section{ACKNOWLEDGMENTS}

The authors acknowledge the funding granted by Project FONDECYT 11060463 , which made the present study possible.

\section{REFERENCES}

[1] a) R. Noyori, Asymmetric Catalysis in Organic Synthesis, Wiley: New York, 1994. b) Carprio V., Williams J. M.J.; "Catalysis in Asymmetric Synthesis", Wiley, Chichester, 2009.

[2] L. Pu, H.-B. Yu, Chem. Rev. 101, 757, (2001).

[3] K. Soai, S. Niwa, Chem. Rev. 92, 133, (1992).

[4] E. N. Jacobbsen, A. Pfaltz, H. Yamamoto (Eds.) Comprehensive Asymmetric Catalysis, Springer: New York, 1999

[5] P. Salehi, M. Dabiri, G. Kozehgary, M. Baghbanzadeh, Tetrahedron: Asymmetry 20, 2609, (2009).

[6] M.N. Patil, R.G.Gonnade, N.N.Joshi, Tetrahedron 66, 5036, (2010).

[7] D. J. Ramon, M. Yus, Chem. Rev. 106, 2126, (2006).

[8] J.-S. You, M.-S. Shao, H.-M. Gau, Organometallics 19, 3368, (2000).

[9] J. González-Sabín, V. Gotor, F. Rebolledo, Tetrahedron: Asymmetry 17, 449, (2006).

[10] a) A. R. Abreu, M. Lourenco, D. Peral, M.T.S. Rosado, M. E.S. Eusebio, O. Palacios, J. C. Bayon, M. M. Pereira, Journal of Molecular Catalysis A: Chemical 325, 91, (2010). b) A. R. Abreu, M. M. Pereira, J. C. Bayón, Tetrahedron 66, 743, (2010).

[11] X. Chen, Q. Liu, H.-B. Sun, X.-Q. Yu, L. Pu, Tetrahedron Letters 51, $2345,(2010)$.

[12] A. Kozakiewicz, M. Ullrich, M. Wełniak, A. Wojtczak. Journal of Molecular Catalysis A: Chemical 326, 128, (2010).

[13] S. Gou, Z. M. A. Judeh, Tetrahedron Letters 50, 281, (2009).

[14] T. Bauer, S. Smolinski, Applied Catalysis A: General 375, 247, (2010).

[15] J. Parada, J. Herrera A. Pedraza, J. Braz. Chem. Soc 20, 74, (2009).

[16] a) E.Fischer, H. North, Ber , 51 , 321, (1918). b) H. Ohle, E. Dickhause, Ber 58, 2593, (1925).

[17] K.R.K. Pradad, N.N. Joshi, J. Org.Chem.62, 3770, (1997).

$$
\begin{aligned}
& \mathrm{R}=\mathrm{Ph} \\
& \mathrm{OPr}=\mathrm{O} \mathrm{Pr}
\end{aligned}
$$

Scheme 2

\section{CONCLUSIONS}

The catalytic systems of derivatives $\mathbf{1}$ and $\mathbf{2}$ and Ti(IV) give high conversion of benzaldehyde to 1-phenyl-1-propanol. The presence of Ti(IV) allows a high yield in the reaction. However, the presence of derivatives 1 and $\mathbf{2}$ controls the enantioselectivity. The high conversion and moderate stereoselectivity involve the formation, within the reaction, of catalytic dimeric species of the type Ti(IV)-carbohydrate $\mathbf{1}$ or $\mathbf{2}$. The Ti(IV)-carbohydrate $\mathbf{1}$ or $\mathbf{2}$ are efficient in enantioselective addition of $\mathrm{Et}, \mathrm{Zn}$ to benzaldehyde with excess of Ti(IV) relative to derivative $\mathbf{1}$ and $\mathbf{2}$ (10-fold) and with substoichiometric amounts of derivatives $\mathbf{1}$ and $\mathbf{2}$ (10\% mmol relative to aldehyde). Under these conditions, the Ti(IV)-carbohydrate catalytic dinuclear species would be preferred in relave to other metal complexes which do not catalyze the reaction. The highest enantioselectivity was with the Ti(IV)-carbohydrate 2 system, where carbohydrate $\mathbf{2}$ is a bidentate ligand. The arrangement of $\mathrm{OH}$ groups of carbohydrate ( 2 or $\mathbf{3}$ ) was crucial in determining the $\mathrm{R}$ or $\mathrm{S}$ preference of 1-phenyl-1-propanol. 